\title{
The study on role of surgical management of clavicle fracture in adults
}

\author{
Lokesh Holagundi ${ }^{*}$, Deepak $\mathrm{S}^{* *}$, Ramachandra $^{* * *}$,Dayanand \\ *senior resident.Bangalore medical college and research centre. Bangalore. \\ **Associate professor \\ ***Assistant professor
}

\begin{abstract}
INTRODUCTION; Clavicle fracture is a common traumatic injury around shoulder girdle due to their subcutaneous position. It is caused by either low-energy or high-energy impact. Fracture of the clavicle accounts for approximately 5 to $10 \%$ of all fractures and upto 44\% of injuries to the shoulder girdle. About $80 \%$ of these fractures are in the middle third of the bone and less often in the lateral third (15\%) and medial third (8\%).AIMS AND OBJECTIVES;To study the role of open reduction and internal fixation in clavicular fractures, study various surgical procedures over fracture clavicle, clinically evaluate the results of various surgical procedures over fracture clavicle,discuss merits and demerits of the various surgical procedures, finally draw conclusions of overall study.METHODOLOGY; The present study was carried out from June2010 to December 2013 at Orthopaedics Department Bangalore medical college and research institute, in this period 40 patients of clavicular fractures were treated surgically. Adult male and female patients above 18 years who require surgical intervention for displaced andcomminution fracture. RESULTS AND OBSERVATIONS; we had 32 cases of middle third clavicle fracture and 8 Lateral third fracture with no medeal third fracture. . The functional outcome is assessed by constant and murleyscore.In this study on 32 patients (80\%) with middle third clavicle fracture treated with plate and screws 24 patients (60\%) had excellent functional outcome, good functional outcome in 6 patients (15\%) and fair functional outcome in 2 patient.For 8 patients of lateral third clavicle fracture fixed with Kirschner wire and tension band wire 4 patients (10\%) had excellent functional outcome results and 2patients (5\%) had good functional outcome 1 patient had fair functional outcome and with 1 patient fixed with hook plate had fair functional outcome.CONCLUSION; Clavicle fractures are usually treated conservatively but there are specific indications for which operative treatment is needed like comminuted, displaced middle third clavicle fractures and displaced lateral third clavicle fracture.In this study primary open reduction and internal fixation with plate and screws of fresh middle third clavicle fractures provides a more rigid fixation and does not require immobilization for longer periods. In this study locking compression plates were used as it is provides strong fixation due to locking between the screw and plate, Dynamic compression plate is strong but it gives excessive prominence through the skin and it is difficult to contour. For displaced, comminuted middle third clavicle fracture plate and screws fixation and early mobilization gave excellent results.

Keywords; clavicle fracture, displaced and comminuted
\end{abstract}

\section{Introduction}

Clavicle is the bony link from thorax to shoulder girdle and contributes to movements at shoulder girdle. Clavicle fracture is a common traumatic injury around shoulder girdle due to their subcutaneous position. It is caused by either low- energy or high- energy impact. Fracture of the clavicle accounts for approximately 5 to $10 \%$ of all fractures and upto $44 \%$ of injuries to the shoulder girdle. About $70 \%$ to $80 \%$ of these fractures are in the middle third of the bone and less often in the lateral third (12\% to $15 \%)$ and medial third (5\% to $8 \%$ ). Fractures of the clavicle have been traditionally treated non-operatively. Although many methods of closed reduction have been described, it is recognized that reduction is practically impossible to maintain and a certain amount of deformity and disability is expected in adults1. In the past few years several publications have described about poor outcomes like malunion and nonunion (15\%) afterconservative treatment of severely displaced clavicular fractures.

AIMS AND OBJECTIVES; To study the role of open reduction and internal fixation in clavicularfractures,various surgical procedures over fracture clavicle.,clinically evaluate the results of various surgical procedures over fracture clavicle. To discuss merits and demerits of the various surgical procedures.finally draw conclusions of overall study. 


\section{Methodology}

The present study was carried out from June2010 to December 2013 at Orthopaedics Department of orthopaedics,Banglore medical college and research institute,Bangalore.During this period 40 patients of clavicle fractures were treated surgically.

Inclusion criteria :Adult male and female patients above 18 years who require surgical intervention for Robinsons ${ }^{8}$ type $2 \mathrm{~B}$ and $3 \mathrm{~B}$ displacement and comminuted middle third clavicle fracture and displaced lateral third clavicle fracture were included for this study after taking written consent from them.

Exclusion criteria :Patients less than 18 years of age ,Patients not willing for surgery and Patients medically unfit for surgery.

General information like name, age, sex, occupation and address were noted. Then a detailed history was elicited regarding mode of injury like fall on the shoulder, Road traffic accident, direct injury to shoulder and fall on outstretched hand. Enquiry was made to note site of pain and swelling over the affected clavicle. Past medical illness and family history were also recorded.General condition of the patients was examined for pallor, pulse rate and blood pressure. Respiratory and cardio vascular system were examined for any abnormalities.consent for surgery taken then proceeded.

Post Operative care :Patients were kept nil orally for 4 to 6 hours post-operatively. Intravenous fluids were given as needed. Antibiotics were continued for 10 days. Analgesics and tranquilizers were given according to the needs of the patient. The operated upper limb was immobilized in an arm pouch. Check x-rays were taken to study the alignment of fracture fragments. The wound was inspected at 3or 4th postoperative day. Suture removal was done on 10th postoperative day. Patients were discharged with the arm pouch.

Rehabilitation of the affected arm was started at the end of 2 weeks. Gentle pendulum exercises to the shoulder in the arm pouch were allowed. At 4 to 6 weeks gentle active range of motion of the shoulder was allowed but abduction in limited to 80 degrees. At 6 to 8 weeks active range of motion in all planes were allowed.

Follow up :Regular follow up for every 4 weeks was done. Local examination of the affected clavicle for tenderness, instability deformity and shoulder movements were assessed. X-rays were taken at each follow up visits to known about progressive fracture union and implant position. Rehabilitation of the affected extremity were done according to the stage of fracture union and time duration from day of surgery. Patients were followed up till radiological union occure. The functional outcome were assessed by Constant and Murley ${ }^{9}$ score.

\section{Results And Observations;}

The present study consists of 40 patients of fresh fracture of the clavicle which were treated surgically with plate and screw for middle third clavicle fracture and Kirschner wire with tension band wire for lateral third clavicle fracture between June 2010 to December 2013.

Following observation are made in our study.In this present study there were 32 patients (80\%) of middle third clavicle fracture and 8 patients $(20 \%)$ were lateral third clavicle fracture and there were no medial third clavicle fracture. All the patients in both middle and lateral third clavicle fracture were closed type. There were no associated medical illness in any patient.In middle third clavicle fractures direct injury occurred in 30 patients among them $10(25 \%)$ patients were due to fall on shoulder from two wheeler, $18(45 \%)$ patients were due to road traffic accident, $2(5 \%)$ patients were due to fall on shoulder after simple fall. In direct injury occurred in $1(2.5 \%)$ patients due to fall on outstretched hand and in 1 patient injury occurred by hitting train while crossing track.In lateral third clavicle fractures direct injury occurred in all 8 (20\%) patients, among them $2(5 \%)$ patients were due to fall on shoulder from height, and 6(15\%) patients due to road traffic accident.Majority of the patients with middle third clavicle fracture i.e.12 patients (30\%) were in the age group of 19-29. The youngest patient was 19 years and oldest patient was 63 years. The average patient was 35.65 years.Most patients 3 cases $(7.5 \%)$ with lateral third clavicle fracture was between $\mid 30-39$ years. The youngest patient was 27 years and oldest patient was 57 years with average age of 37.5 years.In middle third clavicle fracture majority were males,28 patients $(70 \%)$ and females were 4 patients (10\%) .In lateral third clavicle fracture majority were males, 6 patients $(15 \%)$ and females Were 2 patients(5\%).In this study for middle third clavicle fractures there were 18 patients (45\%) of right sided and 14 patients (35) of left sided fracture.For lateral third clavicle fracture there were 4 patients $(10 \%)$ on left side and 4 patients $(10 \%)$ on the right side.In middle third clavicle fracture 8 patients (20\%) had associated injuries among them 2 patient (5\%) had scapular body fracture and 2patient (5\%) had rib fracture 1 patient had ipsilatral ulna shaft fracture and 1 patient had distal radius fracture and 1 patient had glenoidfossa fracture and 1 patient had brachial plexeus injury . 
In Lateral third clavicle fracture 3 patients $(7.5 \%)$ had associated injuries. 2 patients $(5 \%)$ had scapular body fracture and another 1patient $(5 \%)$ had rib fracture. All the Patients were immobilized in an arm pouch.we followed Robinson classification, There were no type-1 (medial third) fracture. In type-2 middle third fracture type-2 B1 (displaced with simple or single butterfly fragment) occurred in 12 patients (30\%) and type-2 B2(displaced with comminuted or segmental) fracture occurred in 20 patients $(50 \%)$.In lateral third clavicle fracture there were type- 3 B1 (displaced with extra articular) occurred in 6 patients (15\%) and type-3 B2 fracture (displaced with intra articular) occurred in 2 patients $(5 \%)$.In 6 patients $(15 \%)$ reconstruction plates were used. In 20 patients (50\%) locking compression plates were used. In 6 patients (15\%) dynamic compression plates were used. Commonly locking compression plates were used.

One reconstruction plate breakage occurred after 6 months due to road traffic accident.

DURATION OF UNION, The fracture was considered to be united when clinically there was no tenderness, radiologically the fracture line was not visible and full unprotected function of the limb was possible.In middle third clavicle fracture 28 patients $(70 \%)$ united at the end of 12 weeks.In 4patients $(10 \%)$ delayed union occurred. It was due to large butterfly fragment at fracture site which united at 16 weeks.In lateral third 7 patients united at the end of 12 weeks.In 1 patient (treated with hook plate) united at the end of 14 weeks. We advise the patient for removal of the plate at the end of 1 year.For 6 patients implant removal done .Remaining patient has not turned up for implant removal.

COMPLICATIONSin our study like any other surgical procedure was found.some are major and some minor. In middle third clavicle fixation 4 patients $(10 \%)$ had hypertrophic skin scar and in 6 patients $(15 \%)$ plate prominence occurred.In 2patients restriction of shoulder movements occurred. In 4 patients $(10 \%)$ delayed union occurred. In 1 patient $(2.5 \%)$ plate loosening occurred which went for malunion and in 1 patient $(2.5 \%)$ plate breakage occurred.In 1 patient $(2.5 \%)$ superficial infection occurred which was treated with oral antibiotics for 5 days and in another 2 patient $(5 \%)$ restriction of shoulder movements occurred due to associated glenoidfossa fracture. The patient was not able to follow the shoulder exercises because of pain.In 1 patient (2.5\%) delayed union occurred.The functional outcome is assessed by constant and murley score.In this study on 32 patients $(80 \%)$ with middle third clavicle fracture treated with plate and screws 24 patients $(60 \%)$ had excellent functional outcome, good functional outcome in 6 patients $(15 \%)$ and fair functional outcome in 2 patient.

For 8 patients of lateral third clavicle fracture fixed with Kirschner wire and tension band wire 4 patients $(10 \%)$ had excellent functional outcome results and 2patients $(5 \%)$ had good functional outcome 1 patient had fair functional outcome and with 1 patient fixed with 4 hole hook plate had fair functional outcome due to associated scapula body fracture.

\section{Discussion;}

Clavicle fractures are usually treated conservatively. In a study conducted to analyze the results of conservative treatment by Hill et $\mathrm{al}^{1}$, Nordqvist et $\mathrm{al}^{2}$ and Robinson et $\mathrm{al}^{3}$ found poor results following conservative treatment of displaced middle third clavicle fracture. Conservative treatment of displaced lateral third clavicle fracture has higher rate of non union and residual shoulder dysfunction as showed by Edwards et $\mathrm{al}^{4}$.In this present study middle third clavicle fracture patients with Robinson Type-2 B2 (Displaced with simple or butterfly fragment) were more common and there were 20 patients (50\%). Type-2 B1 (displaced with comminution) occurred in 12 patients (30\%).In Bostman et $\mathrm{al}^{5}$ study also Robinson type-2B1 was common in 81 patients $(78.64 \%)$. Robinson type-2 B2 occurred only in 22 patients $(21.36 \%)$.In lateral third clavicle fracture patients with Robinson Type-3 B1 (Displaced With extra articular) were more common and there were 6 patients (15\%). Type-3 B2 (displaced with intra articular) occurred in 2 patients (5\%).In Kao et al ${ }^{6}$ series also all the 12 patients belong to Robinson type-3 B1 (Neers type-II).In this study the middle third clavicle fractures were fixed with reconstruction plate in 6 patients (15\%). Locking compression plate in 20 patients $(50 \%)$ and dynamic compression plates in 6 patients(15\%).Locking compression plate was used commonly because precontoured to the shape of the clavicle and provide stable fixation.This in comparison with Bostman et $\mathrm{al}^{5}$. study were reconstruction plates were used in 46 patients $(44.66 \%)$. Dynamic compression plates were used in 55 patients $(53.40 \%)$ and semi tubular plates in 2 patients $(1.94 \%)$. In the initial period of his study dynamic compression plates were used then in later part of his study reconstruction plates were used. Later found there was no difference in the complication rate between the patients treated by dynamic compression plate and reconstruction plate.In this study majority of the middle third clavicle fracture 28 patients (70\%) united at the end of 12 weeks. In 4patients $(10 \%)$ delayed union occurred. It was due to large butterfly fragment at fracture site which united at 16 weeks. There were no non-union.Lazarus $\mathrm{MD}^{7}$ stated radiological union occurred approximately between 6 to 12 weeks. In lateral third 7 patients united at the end of 12 weeks.In 1 patient 
(treated with 4 hole dynamic compression plate) united at the end of 16 weeks.In Kao et $\mathrm{al}^{6}$ series union occurred after an average period of 4 months .Bostman ${ }^{5}$ series had similar union period like our study.

\section{Conclusion}

- Clavicle fractures are usually treated conservatively but there are specific indications for which operative treatment is needed like comminuted, displaced middle third clavicle fractures and displaced lateral third clavicle fracture.

- Among the internal fixation methods intramedullary fixation do not control rotation so they require longer period of immobilization till union.

- In this study primary open reduction and internal fixation with plate and screws of fresh middle third clavicle fractures provides a more rigid fixation and does not require immobilization for longer periods.

- In this study locking compression plates were used as it is provides strong fixation due to locking between the screw and plate, and blood supply preservation due to minimal contact between plate and cortical bone and precontured to the shape of the clavicle, side specific and provide stable fixation. It is necessary to put the plate superiorly and atleast three screws to be applied medially and three screws laterally.

- Semitubular plates were not used because it was difficult to contour and less stress resistant.

- Dynamic compression plate is strong but it gives excessive prominence through the skin and it is difficult to contour.

- All the fractures united and there was no non union.

- Implant removal wereadvisible for all the cases after union

- For displaced lateral third clavicle fractures in a small study of patients, fixed with Kirschner wire with tension band wiring and with 4 hole hook plate early mobilization gave excellent results.

\section{Bibliography}

[1]. Hill JM, Mc Guire MH, Crosby LA. Closed treatment of displaced middle third fractures of the clavicle gives poor results. J BoneJoint Surgery (Br), 1997; 79 :537-540.

[2]. Nordgvist A, Petersson CJ, Redlund-Johnell I. Mid clavicular fractures in adults : end result study after conservative treatment . J Orthop Trauma, $1998 ; 12: 572-576$.

[3]. Robinson CM, Court Brown CM, McQueen MM, Walkefield AE. Estimating the risk of non union following non operative treatment of a clavicular fracture. J Bone Joint Surgery (Am), 2004; $86: 1359-1365$.

[4]. Edwards DJ, Kavanagh TG, Flannery MC. Fractures of the distal clavicle a case for fixation. Injury, 1992; $23: 44-46$.

[5]. Bostman O, Manninen M, Pihlajamaki H. Complications of plate fixation in fresh displaced mid clavicular fractures. J Trauma, 1997; 43:778-783.

[6]. Kao FC, Chao E K, chen CH, Yu SW, Chen CY, Yen CY. Treatment of distal clavicle fracture using Kirschner wire and tension band wires.J.Trauma, 2001;51:522-525.

[7]. Lazarus MD. Fractures of the Clavicle. Chapter-26, In :Bucholz RW and Heckman JD, editors, Rockwood and Green's fractures in adults, 5th edition, Philadelphia : Lippincott Williams and Wilkins, 2001; 1041-1078.

[8]. Robinson's CM. Fractures of the clavicle in the adult. Epidemiology and classification.J Bone Joint Surgery (Br), 1998; 80: 476-484.

[9]. Constant CR, Murley AHG. A clinical method of functional assessment of the shoulder.Clinical Orthopaedics and Related Research.1987; 214: 160-164

[10]. Kelly L. Vander Have, MD, Aaron M. Perdue, MD,Michelle S. Caird, MD, and Frances A. Farley, MD. Operative Versus Nonoperative Treatment of Midshaft Clavicle Fractures in Adolescents J PediatrOrthop 2010;30:307-312).

[11]. Canadian Orthopaedic Trauma Society. Nonoperative treatment compared with plate fixation of displaced midshaftclavicular fractures. A multicenter, randomized clinical trial. J Bone Joint Surg Am. 2007;89A:1-10.

[12]. McKee MD, Pedersen EM, Jones C, et al. Deficits following nonoperative treatment of displaced midshaftclavicular fractures. J Bone Joint Surg Am. 2006;88A:35-40. 